\title{
Delayed post-traumatic stress and memory inflation of life-threatening events following a natural disaster: prospective study
}

Trond Heir, Ajmal Hussain, Pål Kristensen and Lars Weisæth

\section{Background}

The causes of delayed post-traumatic stress disorder (PTSD) are debated, and the validity of late-onset PTSD has been questioned.

\section{Aims}

We aimed to examine predictors of delayed PTSD in a community sample of survivors of a natural disaster.

\section{Method}

Norwegian survivors of the 2004 Indian Ocean tsunami $(n=532)$ responded to a questionnaire at 6 and 24 months post-disaster. The questionnaire measured PTSD symptoms, recalled exposure and immediate stress responses to the disaster, recalled perceived life threat, personality dimensions, social support and other subsequent adverse life events.

\section{Results}

When dichotomising PTSD symptom scores, 331 participants had low and 194 had high PTSD scores (early-onset PTSD) at 6 months. Of those with initially low scores, 43 (13.0\%) had high symptom scores (delayed PTSD) at 24 months. The delayed PTSD group had a lower degree of initially assessed threat and witness experiences of death or suffering, lower immediate stress response and higher degree of memory inflation of perceived threat than the early-onset PTSD group. Among those with low
PTSD scores at 6 months, onset of delayed PTSD was associated with neuroticism and memory inflation of life threat, but not with the degree of initially assessed disaster exposure or reports of subsequent adverse life events.

\section{Conclusions}

Lack of association between trauma exposure and delayed onset of PTSD symptoms casts doubt on whether the traumatic event is actually the primary causative factor for delayed PTSD. Our findings suggest that delayed PTSD may be a manifestation of personality factors and memory inflation of the severity of an event.

\section{Keywords}

Post-traumatic stress disorder; aetiology; epidemiology; trauma; diagnostics.

\section{Copyright and usage}

(C) The Author(s), 2021. Published by Cambridge University Press on behalf of the Royal College of Psychiatrists. This is an Open Access article, distributed under the terms of the Creative Commons Attribution licence (http://creativecommons.org/ licenses/by/4.0/), which permits unrestricted re-use, distribution, and reproduction in any medium, provided the original work is properly cited.
Delayed-onset post-traumatic stress disorder (PTSD) has been a subject of discussion since it was included with the original definition of PTSD in the DSM-III. According to the DSM-5, PTSD with delayed expression occurs when the full diagnostic criteria are not met until at least 6 months after the traumatic event. ${ }^{1}$ Systematic reviews indicate that delayed PTSD accounts for approximately $25 \%$ of those who develop PTSD. ${ }^{2,3}$ Various theories have been put forward to explain the delay in PTSD, usually without strong evidence in favour of the explanation. ${ }^{4}$ The strongest evidence is for the possibility that delayed PTSD may be the result of additional stressors in the aftermath of the trauma. ${ }^{5,6}$ Sceptics have criticised the empirical basis for the diagnosis, as well as the fact that trauma is the main causal factor. ${ }^{7,8}$ Others have suggested that delayed PTSD might be a culturally bound expression. ${ }^{9}$ Thus, there is a need to clarify whether there are differences between trauma survivors who develop early-onset PTSD and delayed PTSD, and what characterises those who develop delayed PTSD compared with those who do not get PTSD.

\section{Memory amplification of life threat}

In a previous follow-up study of Norwegian tourists who experienced the 2004 Indian Ocean tsunami, we showed that recalled severity of life threat increased over time in a significant proportion of the survivors. ${ }^{10}$ The findings led to an editorial in British Journal of Psychiatry, in which Greenberg and Wessely suggested that memory amplification of the severity of the event could be a causal mechanism for delayed PTSD. ${ }^{11}$ In the present study, we wanted to test this hypothesis by re-analysing our previous data. In addition to the changes in memory of life threat, we wanted to study PTSD risk factors established in the literature, such as trauma exposure, peri-traumatic responses, female gender, low education, unemployment, subsequent stressful life events, personality factors and lack of social support. ${ }^{12,13}$ We hypothesised that survivors with delayed PTSD had lower levels of trauma exposure than those with early-onset PTSD, and that they had greater memory inflation of the severity of the event than those who did not develop PTSD.

\section{Aim of the study}

The aim of the study was to examine what characterises those with early-onset PTSD, delayed PTSD and no PTSD. Based on follow-up assessments at 6 and 24 months, we also wanted to examine predictors for the development of delayed PTSD among those with low symptom scores at 6 months.

\section{Method}

\section{Study design}

The study had a longitudinal design in which disaster survivors responded to a questionnaire administered at 6 and 24 months after the disaster. Data on background variables, disaster exposure and post-traumatic stress reactions were obtained. ${ }^{14}$ 


\section{Study population}

Potential participants were Norwegian tourists over 18 years of age, who had visited the areas of Khao Lak, Phi Phi Islands, Krabi province or Phuket in Thailand, during the 2004 Indian Ocean tsunami. A total of 1511 people were eligible for our study, according to lists provided by the Norwegian police who registered all Norwegian citizens who had stayed in the disaster area during the tsunami. Of these, $643(42.6 \%)$ responded at 6 months, $816(54.0 \%)$ responded at 24 months and $532(35.2 \%)$ responded at both waves of assessment. People who had visited the areas that were most severely affected had a much higher response rate, whereas those who had visited less severely affected locations had correspondingly lower response rate. ${ }^{14}$ Also, telephone calls to a random sample of nonrespondents showed that they were less likely to have been exposed to the disaster than responders. ${ }^{15}$ The most common reasons reported for non-participation were limited interest or time, or being unaffected by the tsunami.

We excluded seven individuals from those who responded to both waves of assessments, because of missing data. The remaining 525 participants were similar in age (mean 44.0 years), but there was a slightly higher proportion of women (55\%) than in the 986 individuals who were not included. ${ }^{10}$ Also, the 525 participants did not differ significantly in education level $(57 \%$ had $>12$ years of education), employment ( $73 \%$ were employed), family constellations (69\% were married or cohabitant) or pre-disaster contact with health professionals, compared with the 402 individuals who responded only at the first or second assessment. The stated lifetime prevalence for contact with a general practitioner, psychologist or psychiatrist for reasons of mental health before the tsunami was $23 \%$. The study sample was like the age- and gender-adjusted Norwegian population in employment and marital status, but had a higher level of education and were more involved in family constellations with children. ${ }^{16}$

The study was approved by the Regional Committee for Medical Research Ethics and the Norwegian Data Inspectorate (project number 12858). All participants provided written informed consent through the questionnaire.

\section{Measures}

Post-traumatic stress

We categorised participants into early-onset PTSD, delayed PTSD and no PTSD, according to whether the participants reported high or low symptom scores on post-traumatic stress at the 6- and 24-month assessments post-disaster. At both waves of assessment, we used the 22 -item Impact of Event Scale - Revised (IES-R) ${ }^{17}$ to assess post-traumatic stress symptoms during the past week. Based on their experiences with the tsunami, the participants responded on a five-point Likert scale (0-4). We used the total score of IES-R as a semi-continuous measure of symptom severity, in the possible range $0-88$. We replaced a missing response with a score from the same subject on another item that, on the sample level, had the highest correlation coefficient ( $\kappa$-value) with the item that was missing. We excluded participants from analyses when they had $\geq 25 \%$ missing data $(n=7)$. High versus low PTSD symptom scores were defined as whether the participants had an IES-R score of $\geq 33$, which is a recommended cut-off for the best diagnostic accuracy of PTSD. ${ }^{18}$

\section{Exposure level and the immediate disaster response}

The 6-month questionnaire included a wide range of disaster exposures, such as whether the respondent was caught, touched or chased by waves; sustained physical injuries; witnessed experiences of death or human suffering; or had a close relative or friend who died. ${ }^{14}$ Participants were also asked whether their immediate responses to the disaster were characterised by fear, helplessness or horror. ${ }^{10}$ Responses were measured on a five-point scale from not at all (0) to intense (3) and extreme (4). A score of 3 or 4 was considered as a positive response. ${ }^{10}$

\section{Recalled perceived life threat}

At both waves of assessment, we measured the threat intensity of the original exposure by the question: 'How great do you think the danger was that you would die?' Responses were given on a fivepoint scale: none (1), small (2), moderate (3), great (4) or overwhelming (5). ${ }^{10}$ We specified change in recalled intensity of life threat from 6 to 24 months as the score at 24 months minus the score at 6 months.

\section{Neuroticism}

Neuroticism was measured with the 44 -item Big-Five Inventory, ${ }^{19}$ which was scored on a seven-point scale from 1 (does not fit) to 7 (fits entirely). In a post hoc evaluation of whether variability in neuroticism reflected trauma exposure or antecedent risk for PTSD, we examined the correlations between disaster exposure and the scores of neuroticism, which revealed low and non-significant correlations ('caught, touched or chased by waves': Spearman's $r=0.05, P=0.25$; 'witnessing dead bodies': Spearman's $r=0.02, P=0.70$; and 'loss of family member or close friend': Spearman's $r=0.02, P=0.70$ ), indicating that assessments of neuroticism were negligibly affected by trauma exposure.

\section{General self-efficacy and social support}

We used the ten-item General Self-Efficacy Scale ${ }^{20}$ to measure selfbeliefs in coping with demands, tasks and challenges of life in general, and the six-item Crisis Support Scale ${ }^{21}$ to measure social support after the disaster. We analysed negative social responses, support satisfaction and positive social support separately. ${ }^{22}$ Selfefficacy items were scored on a four-point scale (1, completely wrong; 2 , quite wrong; 3 , quite right; 4 , completely right), whereas social support items were scored on a seven-point scale, from 1 (never) to 7 (always).

\section{Other life events}

We used the 12-item Life Events Inventory ${ }^{23}$ to assess negative life events experienced in the past 12 months. We also included an additional but separately analysed item: whether the participants had experienced a severe accident, armed robbery, physical violence, rape, war or disaster in the past 12 months. ${ }^{10}$

\section{Statistical analyses}

We classified participants into three symptom groups according to symptom assessments at 6 and 24 months post-disaster: early-onset PTSD, delayed PTSD and no PTSD. Participants were classified as having early-onset PTSD if they had a high symptom score (IES$\mathrm{R} \geq 33$ ) at the 6-month follow-up; delayed PTSD was defined as having a low symptom score (IES-R<33) at the 6-month followup and a high symptom score at the 24-month follow-up; and no PTSD was defined as having low symptom scores at both assessments.

We performed $\chi^{2}$-tests with subsidiary Bonferroni-corrected post hoc tests to compare the three allocated symptom groups with regards to categorical demographic variables, different types of exposure and peri-traumatic responses. We used one-way ANOVAs with subsidiary Bonferroni-corrected post hoc $t$-tests to compare the allocated groups regarding age, life-threat intensity, personality dimensions, self-efficacy and social support. The 


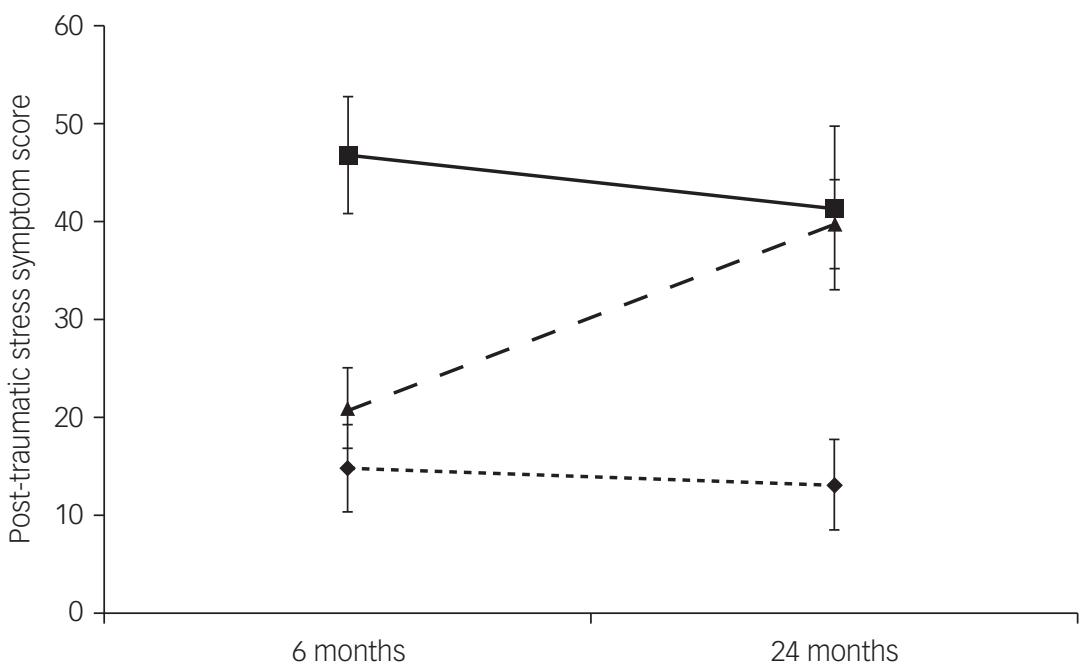

Fig. 1 Post-traumatic stress symptom score (mean total Impact of Event - Scale Revised score with s.d.) in tsunami survivors classified as having early-onset PTSD (squares with solid line; high score at 6 months, $n=194$ ), delayed PTSD (trangles with dashed line; low score at 6 months and high score at 24 months, $n=43$ ) and no PTSD (diamonds with dotted line; low score at both time points, $n=288$ ). Cut-off for high versus low scores was $\geq 33$. PTSD, post-traumatic stress disorder.

distribution of these variables was found to be sufficiently close to the normal distribution for such analyses. ${ }^{24}$

Variables that showed a significant difference between the delayed PTSD group and the no PTSD group were considered as potential predictors of delayed PTSD. This ended up being three variables, all of which were independently subjected to logistic regression in the subpopulation of individuals with initially low PTSD symptom scores. We used the development of delayed PTSD as a dependent variable. We used multiple logistic regression analysis to study adjusted effects of these variables, along with gender and age. We used two-tailed tests and set the significant level at $P=0.05$. Statistical analyses were carried out with the software package SPSS, version 18.0 for Windows.

\section{Results}

Of the 525 participants who completed both waves of assessment, 331 (63\%) had low and 194 (37\%) had high scores (early-onset PTSD) at the 6-month follow-up. Of the 331 participants with low PTSD symptom scores at 6 months, 43 had high scores at the 24-month follow-up (delayed PTSD). Delayed PTSD accounted for $18.1 \%$ of all participants who had high symptom scores at either follow-up. Figure 1 shows the trajectory of PTSD symptom scores in three groups according to whether high symptom scores were early-onset PTSD, delayed PTSD or no PTSD.

Significant differences between the three allocated groups were found for gender and employment (Table 1). The early-onset PTSD group had a higher proportion of women compared with the no
PTSD group. Both the early-onset and delayed PTSD groups had a higher proportion of unemployed participants than the no PTSD group.

\section{Disaster exposure and peri-traumatic responses}

The early-onset PTSD group had been more severely exposed to every type of disaster stressor than either of the two groups that did not have high symptom scores at 6 months (Table 2). The early-onset PTSD group had also been more prone to fear, helplessness and horror during the event. There were no significant differences between the delayed PTSD group and the no PTSD group either in disaster exposure or peri-traumatic responses.

\section{Recalled intensity of perceived life threat}

The early-onset PTSD cases reported a higher degree of life threat at 6 months than either of the two other groups, which did not differ significantly from each other (Table 3). From 6 to 24 months there was an overall memory inflation of perceived life threat, which was most extensive in the delayed PTSD group. When reported at 24 months, there was no significant difference between the earlyand delayed-onset PTSD cases. Both of these groups recalled a higher degree of life threat than the no PTSD group at the 24-month assessment.

\section{Personality factors and social support}

Both the early-onset and delayed PTSD groups had higher levels of neuroticism than the no PTSD group (Supplementary Table 1

Table 1 Demographic data of 525 disaster-exposed Norwegian tourists, according to onset of PTSD after the 2004 Indian Ocean tsunami

\begin{tabular}{|c|c|c|c|c|}
\hline & Early-onset PTSD $(n=194)$ & Delayed PTSD $(n=43)$ & No PTSD $(n=288)$ & Test value $F(2,522)$ or $\chi^{2}$ \\
\hline Age, years, mean (s.d.) & $44.0(13.4)$ & $46.1(14.7)$ & $43.6(12.3)$ & 0.68 \\
\hline Gender, female & $130(67.0)$ & $24(55.8)$ & $138(47.9)$ & $17.12^{\star * *}$ \\
\hline Married or cohabiting & $130(69.9)$ & $25(64.1)$ & $195(70.1)$ & 0.60 \\
\hline Education $>12$ years & $103(53.1)$ & $21(48.8)$ & $177(61.7)$ & 4.91 \\
\hline Employed & $121(62.4)$ & $26(60.5)$ & $234(81.3)$ & $24.20 * * *$ \\
\hline
\end{tabular}


Table 2 Disaster exposure and peri-traumatic responses recalled at 6 months post-disaster in disaster survivors, grouped according to onset of PTSD

\begin{tabular}{|c|c|c|c|c|c|}
\hline & $\begin{array}{l}\text { Early-onset PTSD }(n=194) \\
\qquad n(\%)\end{array}$ & $\begin{array}{c}\text { Delayed PTSD }(n=43) \\
\qquad n(\%)\end{array}$ & $\begin{array}{l}\text { No PTSD }(n=288) \\
n(\%)\end{array}$ & $\begin{array}{l}\text { Test value } \\
\chi^{2}\end{array}$ & $\begin{array}{l}\text { Effect size } \\
\text { Cramér's } V\end{array}$ \\
\hline \multicolumn{6}{|l|}{ Disaster exposure } \\
\hline Caught/touched/chased by waves & $108(55.7)$ & $15(34.9)$ & $92(32.6)$ & $25.98^{\star * *}$ & 0.22 \\
\hline Physical injury inflicted & $40(21.6)$ & $3(7.5)$ & $27(9.5)$ & $15.19 * *$ & 0.17 \\
\hline Witness to dead bodies & $93(52.0)$ & $16(38.1)$ & $91(32.2)$ & $18.00 * * \star$ & 0.19 \\
\hline Witness to survivors with serious physical injuries & $139(76.0)$ & $24(60.0)$ & $156(55.7)$ & $19.77^{\star \star \star}$ & 0.20 \\
\hline Witness to abandoned children & $88(48.6)$ & $9(22.5)$ & $65(23.5)$ & $33.55^{\star * *}$ & 0.26 \\
\hline Loss of family member or close friend & 25 (13.1) & $1(2.3)$ & $13(4.6)$ & $13.78^{* *}$ & 0.16 \\
\hline \multicolumn{6}{|l|}{ Peri-traumatic responses } \\
\hline Fear & $135(75.0)$ & $18(45.0)$ & $128(46.0)$ & $39.57^{* * *}$ & 0.28 \\
\hline Helplessness & $146(80.7)$ & $21(53.8)$ & $139(50.0)$ & $44.54 * * *$ & 0.30 \\
\hline Horror & $18(10.7)$ & $1(2.7)$ & $6(2.3)$ & 15.06 ** & 0.18 \\
\hline
\end{tabular}

Table 3 Recalled intensity of life threat at 6 and 24 months post-disaster in groups of tsunami survivors according to onset of PTSD

\begin{tabular}{|c|c|c|c|c|c|}
\hline & $\begin{array}{l}\text { Early-onset PTSD } \\
\qquad(n=194) \\
\text { Mean (s.d.) }\end{array}$ & $\begin{array}{l}\text { Delayed PTSD } \\
\qquad(n=43) \\
\text { Mean (s.d.) }\end{array}$ & $\begin{array}{l}\text { No PTSD } \\
(n=288) \\
\text { Mean (s.d.) }\end{array}$ & $\begin{array}{l}\text { Test value } \\
F(2,522)\end{array}$ & $\begin{array}{c}\text { Effect size } \\
\eta^{2}\end{array}$ \\
\hline Recalled intensity of life threat at 6 months & 2.20 (1.39) & $1.36(1.43)$ & $1.25(1.27)$ & $29.30 * * *$ & 0.10 \\
\hline Recalled intensity of life threat at 24 months & $2.62(1.12)$ & $2.55(1.26)$ & $1.84(1.18)$ & $22.75^{\star * *}$ & 0.10 \\
\hline Change in recalled intensity of life threat from 6 to 24 months & $0.31(0.80)$ & $1.00(0.95)$ & $0.42(0.85)$ & $8.66^{* * *}$ & 0.04 \\
\hline \multicolumn{6}{|c|}{$\begin{array}{l}\text { Threat intensity was based on the question 'How great do you think the danger was that you would die', measured on a scale of 0-4. PTSD, post-traumatic stress disorder. The early-onset } \\
\text { PTSD group recalled a higher degree of life threat at } 6 \text { months than either of the other groups. At } 24 \text { months, both the early-onset and delayed PTSD groups recalled a higher degree of life } \\
\text { threat than the no PTSD group. The change in recall intensity of life threat from } 6 \text { to } 24 \text { months was higher in the delayed PTSD group than in the other groups. } \\
\star * * * P<0.001 \text {. }\end{array}$} \\
\hline
\end{tabular}

available at https://doi.org/10.1192/bjo.2021.955). Assessments of perceived social support were not significantly different in the delayed PTSD group compared with the no PTSD group (Supplementary Table 1). However, the early-onset PTSD group reported lower levels of positive social support, support satisfaction and self-efficacy than the no PTSD group, and higher levels of negative social response. The early-onset PTSD group also had lower general self-efficacy, whereas there was no difference in self-efficacy between the delayed PTSD group and the no PTSD group.

\section{Additional stressors}

At the 24-month assessment, the three symptom groups differed significantly in negative life events experienced during the previous 12 months $(F=6.18, P<0.01)$. However, the number of such events in the delayed PTSD group (mean 1.2, s.d. 1.4) did not differ significantly from what was reported by the two other groups, whereas the early-onset PTSD group reported a higher number of events (mean 1.5 , s.d. 1.5) than the no PTSD-group (mean 1.0, s.d. 1.3). There were no differences between the three groups in terms of more severe events, such as severe accident, armed robbery, physical violence, rape, disaster or war incidents $\left(\chi^{2}=1.99\right)$.

\section{Predictors of delayed PTSD}

For participants who had low symptom scores at 6 months, delayed PTSD was associated with unemployment, neuroticism and memory inflation of perceived life threat in unadjusted analyses (Table 4). When adjusted for other risk factors, delayed PTSD was associated with neuroticism and memory inflation of perceived life threat.

\section{Discussion}

Our prospective study of disaster survivors showed that delayed PTSD occurred in a community sample that was exposed to a natural disaster. Compared with individuals with early-onset PTSD, those with delayed PTSD had been less exposed to disaster stressors, were less prone to peri-traumatic reactions and reported being exposed to a lower degree of life threat when assessed at 6 months post-disaster. In terms of the severity of disaster experiences, people with delayed PTSD did not differ from those who did not develop PTSD at all. However, from 6 to 24 months there was an overall memory inflation of recalled life threat, which was most extensive in the delayed PTSD group. When assessed at 24 months, there was no difference in recalled life threat between the early-onset and delayed PTSD cases. In a multiple regression analysis, which included all participants that had low symptom levels at 6 months, delayed PTSD was associated with neuroticism and memory inflation of perceived life threat.

\section{Trauma exposure}

Consistent with the conclusions of two reviews, ${ }^{2,3}$ delayed PTSD accounted for a considerable part of PTSD cases. However, unlike previous studies, ${ }^{5,6}$ we found no evidence for the significance of additional stressors in the aftermath of the disaster. Overall, the lack of association between level of disaster exposure and development of delayed PTSD raises questions about the dose-response model of PTSD and the validity of the delayed PTSD construct. ${ }^{7,8}$ The limited exposure to disaster stressors was consistent across several types of trauma exposure. Among these, physical injuries and loss of close relatives are relatively factual and objectified information that should be less prone to recall bias. ${ }^{14}$ Our findings contradict results from a study of PTSD in war veterans, ${ }^{25}$ in which delayed PTSD and early-onset PTSD groups reported equal levels of warzone trauma exposure and peri-traumatic reactions. However, in that study, symptom onset dates, trauma exposure and peri-traumatic stress responses were reported retrospectively after the development of delayed PTSD, in some cases many years after the war experiences. The timing at which we assessed trauma exposure and peri-traumatic 
Table 4 Associations between delayed post-traumatic stress disorder (dependent variable) and employment, neuroticism and memory inflation of perceived life threat, along with age and gender (independent variables), among disaster survivors with initially low symptom scores ( $n=331$ )

\begin{tabular}{|c|c|c|c|c|c|c|}
\hline & \multicolumn{3}{|c|}{ Unadjusted results } & \multicolumn{3}{|c|}{ Adjusted results } \\
\hline & Odds ratio & $95 \% \mathrm{Cl}$ & $P$-value & Odds ratio & $95 \% \mathrm{Cl}$ & $P$-value \\
\hline Age (increase of 10 years) & 1.17 & $0.91-1.50$ & 0.231 & 1.28 & $0.93-1.75$ & 0.130 \\
\hline Gender (women versus men) & 1.37 & $0.72-2.62$ & 0.335 & 1.62 & $0.68-3.85$ & 0.273 \\
\hline Employment (no versus yes) & 2.83 & $1.44-5.59$ & 0.003 & 2.18 & $0.88-5.41$ & 0.092 \\
\hline Neuroticism (increase of one point) & 1.60 & $1.20-2.13$ & 0.001 & 1.74 & $1.21-2.51$ & 0.003 \\
\hline Change in recalled intensity of life threat (increase of one point) & 2.04 & $1.33-3.11$ & 0.001 & 2.19 & $1.37-3.50$ & 0.001 \\
\hline
\end{tabular}

stress (i.e. before the expression of delayed symptoms) may be of importance in the interpretation of between-study differences, as trauma memories may inflate with time. ${ }^{26}$

\section{Recalled life threat}

As postulated by Greenberg and Wessely, ${ }^{11}$ delayed PTSD was associated with memory amplification of life threat. When a person's memory changes over time, it is not obvious which memory best represents the objective event.. However, the agreement between the delayed PTSD group's low level of recalled life threat and their reports on a broad spectrum of trauma-related variables gives strong support to the validity of their first report. Later, memory inflation may have occurred through a variety of processes, such as reappraisal or sensitisation. ${ }^{27,28}$ The interaction between the event characteristics and the memory processes may have been influenced by personality factors, secondary gains or factors related to the current needs of an individual. ${ }^{29,30}$ Threat could have been exaggerated depending on how significant the event was in terms of a person's identity, and whether it was assigned a central role in his or her life history. ${ }^{31}$ For example, expectations of reparative efforts by authorities might render survivors vulnerable to deception and frustration at later stages. ${ }^{3}$ Also, memories could have been reconstructed through media exposure or identification with more severely exposed survivors.

Many studies have shown that subjective measures of perceived threat have predicted PTSD symptoms more precisely than have objective measures of danger. ${ }^{32-34}$ Our findings suggest that not only is appraisal of threat a key determinant of PTSD symptoms, but changes in appraisal may also affect the course of symptoms long after the event. This agrees with the mnemonic model, which argues that it is the current memory of the event that determines whether symptoms occur. ${ }^{35}$ According to this view, there is no authentic memory of the original encoding that can be restored, but rather a selective, current memory that can be changed.

Theoretical explanations for the association between delayed PTSD and memory inflation of life threat should also include the possibility of a reverse causality, i.e. that exacerbation of PTSD symptoms may drive memory enhancement. ${ }^{28,36}$ The processes of remembering may be influenced by symptoms that move negative attention or emotions toward the event. In that case, the study provides few clues as to what drives the late onset of PTSD symptoms.

\section{Neuroticism}

Neuroticism remained a strong predictor for the development of delayed PTSD after adjustment for other risk factors. Increased access to emotionally negative information may increase the vulnerability to delayed PTSD, similar to what has been proposed as a possible explanation for depression. ${ }^{37}$ In the same way as the earlyonset PTSD group, the delayed PTSD group was less likely to be employed than the no PTSD group. This is in accordance with findings among war veterans. ${ }^{25}$ The association may be because of personality or cognitive resources of employed individuals versus those who are not employed, or employment may protect against mental distress by providing some sort of resilience. When adjusted for neuroticism, unemployment was not a significant predictor of delayed PTSD, indicating the importance of the personality.

\section{Study benefits and limitations}

Methodological benefits include the invitation of an entire disaster population of Norwegian tourists who were exposed to the same disaster event. Potential traumatisation was less likely to be related to secondary disaster stressors such as loss of home or livelihood. The participants had above-average education and socioeconomic status, and fewer reimbursement motives than war veterans. ${ }^{38}$ Regardless of diagnoses, survivors were offered free medical and psychosocial care by the Norwegian state. ${ }^{39}$

The study has several limitations. First, there were limited response rates. Lack of participation was primarily related to the experience of personal irrelevance, such as no disaster exposure. ${ }^{15}$ Nevertheless, it must be considered that there may be a response bias of unknown magnitude and direction. Second, we only used self-reported measures, and data on disaster exposure and the immediate stress responses were ascertained retrospectively at 6 months post-disaster, which allows for response bias. Assessments of life-threat intensity were based on a rough measure limited to a single item; the measure of change therefore had poor sensitivity and the effect sizes were small. Third, we did not have access to PTSD diagnoses based on clinical interviews. Still, we believe the study provides valid conclusions about a significant increase in the PTSD symptom level that happened at least 6 months after exposure to the disaster. Fourth, as our measurement of neuroticism was done post-disaster, it may be questioned whether elevated scores were affected by trauma exposure or represented an antecedent risk for PTSD. However, low and non-significant correlations between disaster exposure and neuroticism indicate that elevated scores of neuroticism represent primarily an antecedent risk for delayed PTSD rather than being a result of trauma exposure. This agrees with the theory that neuroticism can be identified early in life, and shows stability over time. ${ }^{40}$

\section{Implications}

Verification of a traumatic event is critical when determining a PTSD diagnosis. Also, it is a basic principle in theories of PTSD that the degree of exposure is associated with the likelihood of developing the disorder. ${ }^{13,41,42}$ The lack of association between exposure level and development of delayed PTSD symptoms in our study may raise questions about the appropriateness of the $\mathrm{A} 1$ criterion, ${ }^{43}$ and whether the basis for diagnosis should be the traumatic load of a real event as opposed to memories, which may have acquired traumatic characteristics. Subsequent treatment planning, healthcare rights and disability payments, among other issues, will be affected by such choices. Concerned about the validity of the delayed PTSD construct, Spitzer et $\mathrm{al}^{8}$ have proposed tightening the PTSD criteria, limited to cases in which 'the symptoms develop within a week of the event', or 'if delayed onset, the onset of symptoms is associated 
with an event that is thematically related to the trauma'. Such restrictions would undoubtedly reduce the number of patients with delayed PTSD.

Memory processes that amplify the severity of an event raise questions about the extent to which cultural factors in society, healthcare, and compensation systems influence how people relate to various adverse events. Symptoms of PTSD are higher among individuals who assign a trauma as a turning point in their life story or a central component of personal identity. ${ }^{44,45}$ Attributing the trauma to a more important role in the individual's life may also influence the trajectory of post-traumatic stress reactions. ${ }^{46}$ More longitudinal studies should be conducted to explore the meaning of memory disturbance in such a process.

Health professionals should be aware of dilemmas by promoting the severity of distressing life events. In cognitive therapy, the moderation of negative appraisals of a traumatic event is a recommended approach in PTSD treatment. ${ }^{47}$ The preoccupation with trauma may have an opposite effect. Thus, too much attention to serious life events and their harmful effects on mental health may contribute to higher levels of mental illness in a population. ${ }^{48}$

In conclusion, our findings suggest that delayed onset of clinical levels of PTSD symptoms may not be related to the degree of trauma exposure itself. It seems that memory processes that affect the current recall of the exposure may be of more importance. Additional prospective research should explore how memories may acquire more traumatic characteristics, and examine the influence of social norms, culture and attitudes in this regard.

Trond Heir (D), Section for Trauma, Catastrophes and Forced Migration, Norwegian Center for Violence and Traumatic Stress Studies, Norway; and Institute of Clinical Medicine, University of Oslo, Norway; Ajmal Hussain, Division of Mental Health Services, Akershus University Hospital, Norway; Pål Kristensen, Center for Crisis Psychology, University of Bergen, Norway; Lars Weisæth, Institute of Clinical Medicine, University of Oslo, Norway

Correspondence: Trond Heir. Email: trond.heir@medisin.uio.no

First received 11 Feb 2021, final revision 18 May 2021, accepted 1 Jun 2021

\section{Supplementary material}

Supplementary material is available online at https://doi.org/10.1192/bjo.2021.955

\section{Data availability}

Data are from the 'Tsunami research program', conducted by The Norwegian Centre for Violence and Traumatic Stress Studies. According to the approval from the Norwegian Violence and Traumatic Stress Studies. According to the approval from the Norwegian
Regional Ethics Committee, the data is to be stored properly and in line with Norwegian privacy protection law. Public availability would compromise privacy of the respondents; however, anonymised data is freely available to interested researchers upon request to corresponding author and project leader, T.H., pending ethical approval from our ethics committee.

\section{Acknowledgements}

The authors thank colleges at the Norwegian Center for Violence and Traumatic Stress Studies for support in conducting the study.

\section{Author contributions}

T.H. formulated the research question. T.H., A.H., P.K. and L.W. designed the study. T.H. has analysed the data. All authors have contributed to writing the manuscript and approved the final draft for publication.

\section{Funding}

This work was funded by the Norwegian Directorate of Health and Social Affairs.

\section{Declaration of interests}

\section{References}

1 American Psychiatric Association. Diagnostic and Statistical Manual of Mental Disorders, Fifth Edition (DSM-5). American Psychiatric Publishing, 2013.

2 Andrews B, Brewin CR, Philpott R, Stewart L. Delayed-onset posttraumatic stress disorder: a systematic review of the evidence. Am J Psychiatry 2007; 164: 1319-26.

3 Smid GE, Mooren TT, van der Mast RC, Gersons BP, Kleber RJ. Delayed posttraumatic stress disorder: systematic review, meta-analysis, and meta-regression analysis of prospective studies. J Clin Psychiatry 2009; 70: 1572-82.

4 Bryant RA. Post-traumatic stress disorder: a state-of-the-art review of evidence and challenges. World Psychiatry 2019; 18: 259-69.

5 Bryant RA, Harvey AG. Delayed-onset posttraumatic stress disorder: a prospective evaluation. Aust N Z J Psychiatry 2002; 36: 205-9.

6 Smid GE, van der Velden PG, Lensvelt-Mulders GJ, Knipscheer JW, Gersons BP, Kleber RJ, et al. Stress sensitization following a disaster: a prospective study. Psychol Med 2012; 42: 1675-86.

7 McNally RJ. Progress and controversy in the study of posttraumatic stress disorder. Annual Rev Psychol 2003; 54: 229-52.

8 Spitzer RL, First MB, Wakefield JC. Saving PTSD from itself in DSM-V. J Anxiety Disord 2007; 21: 233-41.

9 Frueh BC, Grubaugh AL, Yeager DE, Magruder KM. Delayed-onset posttraumatic stress disorder among patients in Veterans Affairs primary care clinics. Br J Psychiatry 2009; 194: 515-20.

10 Heir T, Piatigorsky A, Weisæth L. Longitudinal changes in recalled perceived life threat after a natural disaster. Br J Psychiatry 2009; 194: 510-4.

11 Greenberg $N$, Wessely S. The dangers of inflation: memories of trauma and post-traumatic stress disorder. Br J Psychiatry 2009; 194: 479-80.

12 Norris FH, Friedman MJ, Watson PJ, Byrne CM, Diaz E, Kaniasty K. 60,000 disaster victims speak: part I. An empirical review of the empirical literature, 19812001. Psychiatry 2002; 65: 207-39.

13 Galea S, Nandi A, Vlahov D. The epidemiology of post-traumatic stress disorder after disasters. Epidemiol Rev 2005; 27: 78-91.

14 Heir T, Weisæth L. Acute disaster exposure and mental health complaints of Norwegian tsunami survivors 6 months post disaster. Psychiatry 2008; 71: 266-76.

15 Hussain A, Weisæth L, Heir T. Non-response to a population based post disaster questionnaire study. J Trauma Stress 2009; 22: 324-8.

16 Statistics Norway. Population. Statistics Norway, 2020 (https://www.ssb.no/ en/befolkning).

17 Weiss DS. The Impact of Event Scale - Revised. In Assessing Psychological Trauma and PTSD (eds JP Wilson, TM Keane): 168-89. Guilford Press, 2004.

18 Creamer M, Bell R, Failla S. Psychometric properties of the Impact of Event Scale - Revised. Behav Res Ther 2003; 41: 1489-96.

19 John OP, Donahue EM. The Big Five Inventory: Construction and Validation. University of California, Berkeley, Institute of Personality and Social Research, 1998.

20 Schwarzer R, Jerusalem M. Generalized self-efficacy scale. In Measures in Health Psychology: A User's Portfolio. Causal and Control Beliefs (eds J Weinman, S Wright, M Johnston): 35-7. NferNelson, 1995.

21 Joseph S, Andrews B, Williams R, Yule W. Crisis support and psychiatric symptomatology in adult survivors of the Jupiter cruise ship disaster. Br J Clin Psychol 1992; 31: 63-73.

22 Andrews B, Brewin CR, Rose S. Gender, social support, and PTSD in victims of violent crime. J Trauma Stress 2003; 16: 421-7.

23 Brugha T, Bebbington $P$, Tennant $C$, Hurry J. The list of threatening experiences: a subset of 12 life events categories with considerable long term contextual threat. Psychol Med 1985; 15: 189-94.

24 Fagerland MW, Sandvik L. Performance of five two-sample location tests for skewed distributions with unequal variances. Contemp Clin Trials 2009; 30: 490-6.

25 Andrews B, Brewin CR, Stewart L, Philpott R, Hejdenberg J. Comparison of immediate and delayed-onset posttraumatic stress disorder in military veterans. J Abnorm Psychol 2009; 118: 767-77.

26 Van Giezen AE, Arensman E, Spinhoven P, Wolters G. Consistency of memory for emotionally arousing events. Clin Psychol Rev 2005; 25: 935-53.

27 McFarlane AC. The long-term costs of traumatic stress: intertwined physical and psychological consequences. World Psychiatry 2010; 9: 3-10.

28 Brewin CR. The nature and significance of memory disturbance in posttraumatic stress disorder. Annu Rev Clin Psychol 2011; 7: 203-27. 
29 Conway MA, Pleydell-Pearce CW. The construction of autobiographical memories in the self-memory system. Psychol Rev 2000; 107: 261-88.

30 Rubin DC, Siegler IC. Facets of personality and the phenomenology of autobiographical memory. Appl Cogn Psychol 2004; 18: 913-30.

31 Conway MA. Memory and the self. J Mem Lang 2005; 53: 594-628.

32 Perry S, Difede J, Musngi G, Frances AJ, Jacobsberg L. Predictors of posttraumatic stress disorder after burn injury. Am J Psychiatry 1992; 149: 931-5.

33 King DW, King LA, Gudanowski DM, Vreven DL. Alternative representations of war zone stressors: relationships to posttraumatic stress disorder in male and female Vietnam veterans. J Abnorm Psychol 1995; 104: 184-96.

34 Ehlers A, Mayou RA, Bryant B. Psychological predictors of chronic posttraumatic stress disorder after motor vehicle accidents. I Abnorm Psychol 1998; 107: 508-19.

35 Rubin DC, Berntsen D, Bohni MK. A memory-based model of posttraumatic stress disorder: evaluating basic assumptions underlying the PTSD diagnosis. Psychol Rev 2008; 115: 985-1011.

36 King DW, King LA, Erickson DJ, Huang MT, Sharkansky EJ, Wolfe J. Posttraumatic stress disorder and retrospectively reported stressor exposure: a longitudinal prediction model. J Abnorm Psychol 2000; 109: 624-33.

37 Martin M. Neuroticism as a predictor toward depression: a cognitive mechanism. Pers Individ Dif 1985; 6: 353-65.

38 Frueh BC, Hamner MB, Cahill SP, Gold PB. Apparent symptom over-reporting in combat veterans evaluated for PTSD. Clin Psychol Rev 2000; 20: 853-85.

39 Hjemdal OK. The Regular Practitioners Follow-Up of the Tsunami Exposed Individuals (Report no. 1/2007). Norwegian Centre for Violence and Traumatic Stress Studies, 2007 (https://www.nkvts.no/content/uploads/2015/08/tsunamien_fastlegerapport.pdf).
40 Lucas RE, Donnellan MB. Personality development across the life span: longitudinal analyses with a national sample from Germany. J Pers Soc Psychol 2011; 101: 847-61.

41 March JS. What constitutes a stressor? The 'criterion A' issue. In Posttraumatic Stress Disorder: DSM-IV and Beyond (eds JRT Davidson, EB Foa): 37-54. American Psychiatric Press, 1993.

42 Brewin CR, Andrews B, Valentine JD. Meta-analysis of risk factors for posttraumatic stress disorder in trauma-exposed adults. J Consult Clin Psychol 2000; 68: 748-66.

43 Friedman MJ, Resick PA, Bryant RA, Brennin CR. Considering PTSD for DSM-5. Depress Anxiety 2011; 28: 750-69.

44 Berntsen D, Rubin DC. When a trauma becomes a key to identity: enhanced integration of trauma memories predicts posttraumatic stress disorder symptoms. Appl Cogn Psychol 2007; 21: 417-31.

45 Blix I, Solberg O, Heir T. Centrality of event and symptoms of posttraumatic stress disorder after the 2011 Oslo bombing attack. Appl Cogn Psychol 2014; 28: 249-53.

46 Blix I, Birkeland MS, Solberg Ø, Hansen MB, Heir T. The launching and ensnaring effects of construing a traumatic event as central to one's identity and life story. Appl Cogn Psychol 2016; 30: 526-31.

47 Ehlers A, Clark DM. A cognitive model of posttraumatic stress disorder. Behav Res Ther 2000: 38: 319-45.

48 Heir T, Bonsaksen T, Grimholt T, Ekeberg $\varnothing$, Skogstad L, Lerdal A et al Serious life events and posttraumatic stress disorder in the Norwegian population. BJPsych Open 2019; 5(5): e82. 